\title{
Relationships between Eco-Leadership and Problem-Solving Styles of Gifted and Talented Youth
}

\author{
Curtis R. Friedel \\ Assistant Professor \\ Virginia Tech \\ D. Adam Cletzer \\ Assistant Professor \\ University of Missouri \\ Sarah A. Bush \\ Graduate Research Assistant \\ Virginia Tech \\ J. Danielle Barber \\ Graduate Research Assistant \\ Virginia Tech
}

\begin{abstract}
Our understanding of leadership has undergone a significant shift in the early part of the 21 st century. An emerging perspective, dubbed Eco-Leadership, suggests leadership is a collective process involving both leaders and followers co-creating leadership. Because our beliefs and attitudes toward leadership affect how we lead, it becomes crucial to better understand the views youth have towards leadership, as they develop into our future leaders, to improve curricula and instruction. In this study, no relationship was found between youth attitudes and beliefs towards systemic and hierarchical thinking with respect to their preferred problem-solving style. These findings indicate youth may adaptively or innovatively associate leadership equally through systemic and hierarchical thinking. Further, neither being more adaptive nor more innovative implies one to be better at leading.
\end{abstract}

\section{Introduction}

Conflict between two people, or two groups of people, occur often because of differences in perspectives to solve a problem. These differences are sometimes associated with gaps in status, as some individuals have more experiences to justify their solutions to the problem than other individuals. Sometimes, these differences are associated with differences in how values are prioritized within the proposed solution, which is a difference in ideology. However, many times differences in status and ideology are aligned and there is still conflict in proposing a creative solution to the problem, because there is a difference in problem-solving style. Because problemsolving style is a preference to solve problems in a more adaptive or more innovative way (Kirton, 2011), conflict naturally occurs as the couple or groups of people decide which approach may be best for the problem at hand. Recognizing this categorization of differences in how the problem may be perceived is not only useful for leaders and leader educators, but also in 
teaching youth how differences may be navigated so that mutual respect may be maintained during the problem-solving process. As our world's problems become more complex, it becomes more important for our future leaders to understand two fundamental assumptions in addressing these problems. First, all people are creative and can choose to make contributions to solving the problem at hand; and second, complex problems require teams to embrace diversity of thought among team members so that the team may be effective in exhibiting leadership (Kirton, 2011).

Problem solving and leadership are both widely accepted as skills which high school graduates must possess to be successful in the current workforce and in higher education (Hooker \& Brand, 2010). Although problem solving and leadership are often considered as separate concepts, many authors believe they are related. For example, Friedel (2014) wrote, "leadership is dependent on solving a problem" (p. 74). Further, leaders must have knowledge of their leadership capacities in relation to the construction of solutions during while solving a problem (Mumford, Zaccaro, Connelly, \& Marks, 2000). Effective leaders are able to construct teams comprised of individuals with the capacity and problem-solving styles necessary to solve the problem at hand (Kirton, 2011). With this in mind, this study aimed to expand knowledge on the similarities and differences between leadership and problem-solving styles by examining gifted and talented high school students perspectives on leadership while participating in a summer residential program.

Background to the Study. The Virginia Summer Residential Governor's School for Agriculture (VGSA) is a four-week long summer residential program for 100 gifted and talented junior and senior high school students interested in pursuing careers in agriculture. This educational experience aims to develop youth to become leaders as professionals in various careers in the agriculture industry. Part of the program engages participants in a cooperative learning project intended to produce a solution to one of several National Institute of Food and Agriculture (NIFA) research initiatives: climate change, food safety, sustainable energy, global food security and hunger, or childhood obesity (United States Department of Agriculture, 2016). These research-based projects provide VGSA participants with an opportunity to develop team leadership skills through the problem-solving process. This opportunity to complete interdisciplinary STEM-based research in teams gives these students experiences that help them recognize the increasingly complex and interconnected problems related to the future production of food and agriculture. Additionally, participants recognize the importance of diversity of thought based on an individual's values and perspectives, which contribute to addressing these problems. The VGSA curriculum is designed to help participants better understand the global challenges associated with healthy people living on a healthy planet (National Research Council, 2009). However, just as the complex problems associated with the NIFA research initiatives may be difficult to define, there are many theories and principles associated with the leadership development of youth yet to be fully examined.

Eco-Leadership Defined. Our society's understanding of what leadership is, and what a leader should be, has undergone a significant shift in the early part of the 21 st century. Traditional definitions of leadership dating to the 1900s described the phenomenon as "a process whereby an individual influences a group of individuals to achieve a common goal" (Northouse, 2013, p. 3). This understanding of leadership is rooted in what Allen, Stelzner, and Wielkiewicz (1998) call an industrial, or mechanistic, paradigm, which focuses on the preeminence of 
individual positional leaders and the machine-like qualities of organizations.

While such a conceptualization of leadership was appropriate and effective during the Industrial Revolution and the Western world entered the 21st century knowledge-driven economy, the industrial paradigms' reliance on individual leaders to provide 'the leadership' for organizations has been increasingly viewed as untenable in an increasingly complex, interdependent, and modern world.

At the turn of the century, Allen et al. (1998) and others identified an emerging ecological paradigm in leadership studies. The ecological paradigm of leadership focuses on the systemic nature of leadership. Accordingly, leadership is no longer understood as the actions or properties of an individual leader holding a position of authority, but, rather, a collective process that involves both leaders and followers co-creating leadership. Under this paradigm, individual positional leaders still exist, but their new role is to "assist in the emergence of leadership rather than creating change through executive orders and decision" (Wielkiewicz \& Stelzner, 2005, p. 331). This approach enables organizations to harness the talent, creativity, and energy of all employees and stakeholders, rather than relying on an individual, or a small group of leaders to provide leadership (Western, 2013). Because our beliefs and attitudes toward leadership affect how we lead, it becomes crucial to understand how youth view leadership so that curricula and instruction may be improved.

Problem-Solving Style. Kirton (2011) posits that all individuals are creative and solve problems on a daily basis. As we create solutions to problems, we each approach problems with an innate problem-solving style; either being more adaptive or more innovative in one's preference (Kirton, 2011). We now know from 40 years of research, problem-solving style, as it relates to adaption-innovation (A-I) theory, is independent from intelligence, process, motive, attitude, and learned skills. Therefore, we all solve problems, but approach the problem with a preferred style. One's preferred problem-solving style cannot be altered or developed, but rather is constant throughout one's life (Kirton, 2003); this is in contrast to a person's understanding of, and approach to, leadership, which may change as one changes his or her attitudes and beliefs on leadership. Of course, we can all operate more adaptively or more innovatively than our preferred problem-solving style, but this coping behavior (Kirton, 2011) is psychologically expensive to do so. More description of coping behavior is presented subsequently in the discussion of adaption-innovation theory.

With this in mind, we aim to affirm that conceptualization of leaders and leadership specifically, ecological leadership — stands independent from problem-solving style. Previous research revealed no relationship or a negligible relationship among problem-solving style and various other self-assessments, including: creative level, dogmatism, flexibility, self-esteem, goal orientation, leadership practices, etc. (Kirton, 2011). This study stands to displace associations made between problem-solving style and ecological leadership, and to provide support for the notion that all individuals are able to develop the leadership skills needed to be successful. With this in mind, this study supports the National Leadership Education Research Agenda Priority 4: The Sociological Development of the Leader, Learner, \& Follower by providing insight into how problem-solving style and ecological leadership views impact a leader's orientation and approach towards working with a team (Andenoro et al., 2013). 


\section{Purpose and Objectives}

The purpose of this study was to determine if significant relationships existed between preferred problem-solving styles and leadership attitudes and beliefs for high school students participating in VGSA. The study was steered by the following objectives:

1. Describe selected demographic variables, problem-solving styles, and leadership attitudes and beliefs of participants in the VGSA.

2. Examine the differences between gender and leadership attitudes and beliefs of participants in the VGSA.

3. Examine the relationship between VGSA participants' problem-solving styles and leadership attitudes and beliefs.

\section{Literature Review}

Ecological Forms of Leadership. Traditionally, the study of leadership has focused on the characteristics or behaviors of the individual leader in a group (Wielkiewicz, 2002). However, new research has begun to focus instead on "the systems context in which leadership and organizational adaptation takes place" (Wielkiewicz, 2002, p. 108). As the pace of change in the external environment continues to increase, a variety of alternative perspectives on leadership have arisen, including Allen et al.'s (1998) ecological approach. The theory is based on principles of ecology and systems theory, rather than more traditional mechanistic principles (e.g., Capra, 1996; Colarelli, 1998; Katz \& Kahn, 1978; Kelly, Ryan, Altmann, \& Stelzner, 2000). This ecological perspective on leadership put forward by Wielkiewicz (2002) contends that:

No single individual is capable of leading an organization in the sense that the word has traditionally been used because the amount of information that must be processed and the complexity of challenges from the outside of the organization are too enormous. Instead, a successful organization must function like a complex adaptive system. (p. 108)

Instead of fixating on individual positional leaders who function in a top-down, hierarchical manner, organizations are likely to be more successful in adapting to environmental changes if they "draw on ecological principles to match the complexity of the environment in which organizations function" (Wielkiewicz, 2000, pp. 108-109). These new constructs of an ecological perspective of leadership - diversity, feedback loops, increased organizational learning, and systemic thinking — necessitate new measures to help researchers and practitioners study and influence the development of beliefs and skills related to leadership (Wielkiewicz, 2000).

According to the ecological theory of leadership, as described by Allen et al. (1999), the various characteristics of eco-leadership described above can be plotted in their degree on two orthogonal continua: (a) hierarchical thinking and (b) systemic thinking. Hierarchical thinking refers to the degree to which a person believes an organization should be arranged in a hierarchical fashion, with both power and control concentrated in the hands of an upper echelon 
of leaders or a single leader. A highly hierarchical viewpoint stresses rules, procedures, goals, and a general dependence on the leader (Wielkiewicz, 2000). Moreover, adherents to a highly hierarchical view of leadership attribute the responsibility for the success or failure of an organization to positional leaders, as well as charge them with the responsibility for ensuring the safety and security of an organization's members (Wielkiewicz, 2000). This description of a highly hierarchical view of leadership is consistent with a more mechanistic/industrial paradigm of leadership, while a less hierarchical view of leadership is consistent with an ecological paradigm of leadership (Rost, 1997).

Systemic thinking refers to the degree to which an individual or group has the "ability to relate a variety of ideas and concepts to organizational success, such as ethics, the need for cooperation of all individuals to help the organization accomplish goals, the need for long-term thinking, and the need for organization learning" (Wielkiewicz, 2000, p. 341). Individuals with a higher degree of systemic thinking are "least likely to see themselves or positional leaders in the organization as having the capability of single-handedly making all of the key organizational decisions" (Wielkiewicz, 2000, p. 345). According to Allen et al. (1999), organizations with a higher number of systemic thinkers should be most successful. A high degree of systemic thinking indicates a more ecological view of leadership, while a lower degree of systemic thinking indicates a more mechanistic viewpoint (Rost, 1997). There is theoretical reason to believe that attitudes and beliefs associated with hierarchical and systemic thinking will not be correlated with the KAI (Kirton's Adaption-innovation Inventory; Kirton, 2015), as the KAI measures only a preferred style of solving problems, and not the attitudes and beliefs associated with organizational structure. These two scales - hierarchical and systemic thinking - are measured using Wielkiewicz's (2002) Leadership Attitudes and Beliefs Scale III (LABS-III), which is discussed in detail in the methods section of this article.

Adaption-Innovation Theory. "Leaders are faced with complex challenges that call for leadership to span a broad context, create strategic alliances, share leadership responsibilities, and meet the demands of global citizenship" (Hanks, et al., 2015, p.3). Leaders better face these challenges if they better understand how we each differ on how we prefer to solve problems and manage structure. In A-I theory, more adaptive individuals prefer well established and structured situations which allow them to develop creative ideas within the structure for the purpose of making it more efficient (Kirton, 2013). Often, the more adaptive are perceived by the more innovative as detailed, thorough, systemic, and traditional. A more innovative individual, on the other hand, prefers less structured situations where they may develop creative ideas as a chance to setup different structures outside of the current paradigm (Kirton, 2013). More innovative individuals are often perceived by the more adaptive as freethinking, rule-breaking, and unconventional. With this in mind, an individual who is more adaptive, it would seem, may gravitate towards a highly hierarchical view of leadership, which "stresses rules, procedures, goals, and a general dependence on the leader" (Cletzer, 2016, p. 8). More innovative individuals, it would seem, may gravitate toward a highly systemic view of leadership “....where the individual has the ability to relate a variety of ideas and concepts to organizational success. However, they do not believe the positional leader nor themselves can single handedly make all the vital organizational decisions" (Cletzer, 2016, p. 8). These assumed, but theoretically unlikely, connections between A-I theory and approaches to engaging in leadership warrant further investigation. 
An individual's problem-solving style may be measured by completing the KAI, which provides a score that only certified practitioners are permitted to analyze. These problem-solving style differences are innate and located on a normally distributed continuum, ranging from high adaption to high innovation (Kirton, 2015). The theoretical range of the continuum is between 32 and 160 points, with a general population mean of 95 points. Individuals with fewer than 95 points on the KAI are considered more adaptive to the general population, and individuals with more than 95 points are considered more innovative. However, when working in a group setting it is more appropriate to know where you are situated on the continuum based on the members within your group versus the general population. If one group member has a KAI score of 119 this makes the individual more innovative than the general population mean. However, if this same individual is placed in a group where other members have scores of 130 and 142, the individual with the KAI score of 119 is considered the most adaptive individual in the group. Because the KAI measures only an individual's problem-solving style, it is unbiased towards culture, ethnicity, occupation, or value system. Thus, practitioners helping leaders may use the KAI to consider if a cause of conflict may be rooted in the difference in problem-solving styles, or if the conflict may be attributed to another variable of interest.

Empirical evidence indicates individuals with more than a 20-point difference in KAI scores have different problem-solving styles (Kirton, 2011). This difference in preference of how the problem should be solved, adaptively or innovatively, may give rise to difficulties in communicating, working with, and trusting each other (Kirton, 2011). It is important to note, that preferred problem-solving style is not always the exhibited style of the problem-solver. Individuals may operate outside one's preferred problem-solving style either more adaptively or innovatively along the A-I continuum. Kirton (2011) has termed this skill as coping behavior, which requires motivation to enact. While preferred problem-solving style is innate and stable, individuals may learn skills to operate more adaptively or innovatively when the problem solver recognizes the need to do so. If the individual is not motivated enough to use those skills, one will revert back to their preferred problem-solving style. Coping behavior is stressful and taxing for the brain (Kirton, 2011). If the reward of completing the solution is not motivating enough to endure the stress of coping with fellow team members, the team may likely fail in solving the problem; but if the reward of solving the problem is worth the stress of using coping behavior, the team may likely be successful in solving the problem (Kirton, 2011).

While A-I theory has not typically been considered a leadership theory, it may improve our understanding of leadership when used as a cognitive theory. For example, Friedel (2014) suggested that many definitions of leadership tend to be biased towards innovation, while definitions of management tend to be biased towards adaption. Friedel (2014) recognized leadership is the leveraging of cognitive diversity to solve problems, recognizing that cognitive diversity may impede work on solving the problem being tasked. In this connection of leadership and problem solving, Kirton (2013) offers that every time a group solves a problem, there are essentially two problems, Problem A and Problem B. Problem A is the main problem at hand and the initial reason why the team was formulated; whereas, Problem B is any problem that arises which does not help support the solving of Problem A (Kirton, 2013). One common Problem B that impedes solving Problem A can derive from individuals being unwilling to see fellow team member's viewpoints with respect to their differences in problem-solving style with the belief that the other's preference to solve the problem is not only a bad idea, but a bad idea that only 
benefits one or a few of the team members (Kirton, 2011). A team therefore considered successful if it is able to work together with mutual respect and contribute to solving Problem A and proactively try to prevent Problem Bs from getting in the way.

When working with youth, there may be a difference in how two youth leaders perceive Problem A; that is, the possibility of more than a 20-point gap in KAI scores indicating one wants to solve the problem more adaptively and the other wants to solve the problem more innovatively. Due to two individual's differences in preferred problem-solving styles, Problem Bs may result when there is not agreement on how to best solve the problem with both individuals feeling like they contributed and were not equally rewarded. "The larger the gap between individual's scores on the KAI, the greater the problems of them communicating and collaborating. This is true even if the people concerned are all adaptors or innovators" (Kirton, 2009 , p. 16). Thus, problem-solving style gaps of more than 20 points can occur anywhere on the A-I continuum, and may be the reason for the inability to solve Problem A; providing reason to believe that there is a lack of leadership.

Leadership Development. The aforementioned literature supports the value of examining how problem-solving style relates with a preference to a more hierarchical or systemic approach to leadership, with theoretical supposition that there is little relationship between the two measures. With this in mind, it can be assumed that due to all people being creative, all individuals can become leaders. Good leadership skills are not innate; however, it is something that can be taught, learned, or developed and should be viewed as a skill set. Learning to motivate the team to solve Problem A through the mitigation of Problem Bs is an important leadership skill. While there are many models of leadership development, one of particular note is the model for Leadership Development across the Lifespan (Hanks et al., 2015), which suggests leadership instruction should vary depending on the age of the leader. Specifically, for youth aged between 12 to 19 years individuals' transitions to focus on self and identity (Hanks et al., 2015). Adolescents learning to become leaders begin asking the existential questions related to identifying who they are in the world and what do they want to be when they grow up (Hanks et al., 2015). For the first time, individuals are questioning their values and beliefs, which may indicate it is the most pertinent time to teach youth about values associated with good leadership. While there is no evidence that problem-solving style changes as one matures or ages (Kirton, 2011), and can reliably be measured at the age of 17 years (Kirton, 2015), beliefs and attitudes about leadership do change throughout one's life (Hanks et al., 2015). The question then is, what attitudes and beliefs does one have toward systemic thinking and hierarchical thinking, as described by Wielkiewicz (2002), and how does it relate to one's problem-solving style?

\section{Methods and Procedures}

This quantitative, correlational research study sought to describe and compare variables related to problem-solving style and youth's attitudes and beliefs toward leadership within a single population of VGSA students (Ary, Jacobs, \& Sorenson, 2013).

Sample. Researchers recruited participants for the study who were enrolled in the VGSA program. Students participating in VGSA have been identified as gifted and/or talented and have an interest in pursuing a career in agriculture but have little background in agriculture. The 
program requires that they live on a university campus for four weeks, completing coursework with university faculty members and completing a problem-based research project as a team focusing on an assigned NIFA research initiative. The curriculum provides instruction to solve complex problems in teams while providing opportunities for teams to learn how to solve problems together. Due to the small number of participants in VGSA $(N=98)$, the entire group was included as participants in the study.

Data Collection. Two standardized instruments were used to collect data: (a) the KAI (Kirton, 2015), and (b) the Leadership Attitudes and Beliefs Scale-III (LABS-III; Wielkiewicz, 2002).

KAI. The KAI, as previously mentioned, is a measure of problem-solving style. There are 32 assessment items on the KAI, providing a scale range between 32 and 160 points (Kirton, 2015). For each item, participants are asked to mark an "X" on a line between the two anchors of "very hard" and "very easy". Kirton (2015) has provided evidence to support the validity of the KAI and reports of acceptable reliability estimates with various populations. The KAI is typically used with adults and there is a degree of caution in administering the KAI to those under the age of 17 years. Maturity and grasp of the English language are important for improved reliability, but Selby, Treffinger, Isaksen and Powers (1993) found the KAI when used with students as young as eighth grade may maintain an acceptable reliability estimate of .74 to .78 .

The KAI total score includes three summated construct scores, or sub-scores, which provide more in-depth information regarding one's problem-solving style. These three subscales are: "(i) Sufficiency of Originality (SO), dealing with idea generation, (ii) Efficiency (E), dealing with problem solving methodology; and (iii) Rule/Group Conformity (R), dealing with social structure, both of rule (impersonal) and group (personal)" (Kirton, 2015, p. 42).

When collecting data, the KAI was administered via paper instrument, in person, and during a VGSA lecture conducted by one of the researchers. The KAI was presented as part of the VGSA curriculum; total scores and their meanings were later shared with participants as part of their educational experience. Of the 98 VGSA students, 98 responded to the KAI with 75 usable KAI scores, based on scoring criteria.

LABS-III. The LABS-III was originally designed to measure the impact of leadership program interventions on college students' attitudes and beliefs about leadership “in a manner consistent with Allen et al.'s (1998) [ecological] leadership theory" (Wielkiewicz, 2002, p. 109). The LABS-III consists of 28 Likert-type questions on an ordinal, five-point scale ranging from strongly agree to strongly disagree). Both convergent and discriminative validity of the systemic and hierarchical thinking scales have previously been established (Fischer et al., 2014). Also, this instrument is different from most leadership assessments, such as Posner's (2004) Student Leadership Practices Inventory, or Avolio, Sivasubramaniam, Murry, Jung, and Garger's (2003) Team Multifactor Leadership Questionnaire, in that it assesses attitudes and beliefs independent of the individual's participation in a leadership position (Lowhorn, 2011). Respondents need not have held a leadership position in order to respond - nor are responses tied to an experience in a particular organization, or with a particular team and team leader. This is in keeping with the ecological perspective of leadership, which contends that 
leadership should be distributed throughout an organization to include those individuals not holding what has traditionally been considered a "leadership position" (Wielkiewicz \& Stelzner, 2010).

When collecting data, the LABS-III was administered online via Qualtrics, a universitypartnered survey service. Participants were notified during one daily VGSA assembly that the survey would be distributed the next day. An individual link to participate was distributed via email, with a follow-up reminder email being sent one day later. Of the 98 VGSA participants, 96 completed the survey within two days. The survey was closed three days after the initial email invitation was sent.

Data Analysis . Descriptive statistics (i.e., mean, standard deviation, and range) were conducted for all variables, including demographic variables. Pearson's product-moment correlation coefficient was used to determine the strength and direction of the relationship between scores on the KAI and LABS-III. Researchers used a .05 level of significance to identify statistically significant results. Cohen's (1998) classification of effect sizes was used to describe the magnitude of relationships: .10 was described as a small effect size, .30 was described as a medium effect size, and a correlation of .50 or higher was described as a large effect size. Finally, independent samples $t$ tests were conducted to compare LABS-III scale scores across genders. Of the 98 students in the VGSA program, 75 provided useable responses, based on scoring criteria, for both instruments involved in this study.

\section{Results}

Objective one aimed at describing the gender make-up, problem-solving styles, and leadership attitudes and beliefs of the high school students in VGSA. Simple descriptive statistics were used to determine the demographic makeup of participants, including age, gender, and race. Of those 98 respondents, $65.3 \%(n=64)$ were female and $34.7 \%(n=34)$ were male. Ages of participants ranged from 16 to 17, with a median age of 17 years. Respondents reported being 51\% $(n=50)$ Caucasian, 37\% $(n=36)$ Asian, 5\% $(n=5)$ African American, 4\% $(n=4)$ Indian, and $3 \%(n=3)$ other.

The problem-solving style scores of these VGSA students ranged from 52 to 125 on the KAI with a mean score of $94.08(S D=16.35)$; this is similar to a KAI normal distribution, which tends to be reported (Kirton, 2015). VGSA participants ranged from 22 to 59 with a mean of 41.75 ( $S D=8.20$ ) for sufficiency of originality, from 7 to 30 with a mean of $17.51(S D=5.20)$ for efficiency, and from 15 to 55 with a mean of $34.82(S D=7.33)$ for rule/group conformity (see Table 1). These sub-scores are also relatively consistent with the general population expectations (Kirton, 2015). 
Table 1

Means, Standard Deviations, and Range of Problem-solving Style $(n=75)$

\begin{tabular}{lrrrr}
\hline & Min & Max & $M$ & \multicolumn{1}{c}{$S D$} \\
\hline Total KAI Score & 52 & 125 & 94.08 & 16.35 \\
Sufficiency of Originality (SO) & 22 & 59 & 41.75 & 8.20 \\
Efficiency (E) & 7 & 30 & 17.51 & 5.20 \\
Rule/Group Conformity (R) & 15 & 55 & 34.82 & 7.23 \\
\hline
\end{tabular}

Note. KAI scores range from 32 to 160 , SO ranges from 13 to 65 , E ranges from 7 to 35 , and $\mathrm{R}$ ranges from 12 to 60 .

Participants' leadership attitudes and beliefs were assessed utilizing the LABS-III (Wielkiewicz, 2000) questionnaire. The LABS-III utilizes a five-point Likert scale (1- strongly agree, 2 - agree, 3 - neither agree nor disagree, 4 - disagree, 5- strongly disagree) to determine one's hierarchical thinking and systemic thinking scores. It is important to note that individuals low in hierarchical thinking (higher numeric scores) and high in systemic thinking (higher numeric scores) are most closely associated with an ecological view of leadership, while individuals high in hierarchical thinking (lower numeric scores) and lower in systemic thinking (higher numeric scores) are most closely associated with a mechanistic/industrial view of leadership (Wielkiewicz, 2000). For hierarchical thinking, VGSA students ranged from 14 to 59 points with a mean of $38.74(S D=7.66)$. For systematic thinking, participants ranged from 14 to 67 points with a mean of $25.72(S D=6.61$; see Table 2$)$.

Table 2

Means, Standard Deviations, and Range of Leadership Attitudes and Beliefs Scale $(n=96)$

\begin{tabular}{lcccc}
\hline & Min & Max & $M$ & SD \\
\hline Hierarchical Thinking & 14 & 59 & 38.74 & 7.66 \\
Systemic Thinking & 14 & 67 & 25.72 & 6.61 \\
\hline
\end{tabular}

Note. Scale $-1=$ strongly agree, $2=$ agree, $3=$ neither agree nor disagree, $4=$ disagree, $5=$ strongly disagree. Lower scores indicate a higher preference for Hierarchical or Systemic Thinking.

Objective two sought to examine the differences between VGSA students' gender and leadership attitudes and beliefs (see Table 3). There was no statistical difference in gender observed for hierarchical thinking or systemic thinking means. 
Table 3

Differences between VGSA Students' Gender and Leadership Attitudes and Beliefs $(n=96)$

\begin{tabular}{|c|c|c|c|c|c|}
\hline & $N$ & $M$ & $S D$ & $t$ & $p$ \\
\hline \multicolumn{6}{|c|}{ Hierarchical Mean } \\
\hline Male & 16 & 37.25 & 6.14 & -1.02 & .31 \\
\hline Female & 59 & 39.27 & 7.23 & & \\
\hline \multicolumn{6}{|c|}{ Systemic Mean } \\
\hline Male & 16 & 27.44 & 4.94 & 1.92 & .06 \\
\hline Female & 59 & 24.76 & 4.95 & & \\
\hline
\end{tabular}

Note. Significance at the $* p<.05$ level, 2-tailed. Lower scores indicate a higher preference for Hierarchical or Systemic Thinking.

Objective three aimed to observe the relationship between problem-solving style and leadership attitudes and beliefs (see Table 4). There were no significant relationships between hierarchical thinking and KAI scores, nor was there a significant relationship between systemic thinking and KAI scores. While there was a significant relationship between the efficiency subscore of the KAI and systemic thinking $(r=.28, \mathrm{p}<.05)$, it was interpreted as a low correlation. This small correlation may be interpreted as one who may be more innovative in methodology of solving a problem may also place a lower value in systemic thinking; likewise an individual who has a more adaptive methodology of solving a problem may also place a higher value in systemic thinking.

Table 4

Correlations between Problem-solving Style and Leadership Attitudes and Beliefs of VGSA Students $(n=75)$

\begin{tabular}{lcc}
\hline & Hierarchical Thinking & Systemic Thinking \\
\hline Total KAI Score & .11 & -.05 \\
Sufficiency of Originality (SO) & .02 & -.14 \\
Efficiency (E) & .22 & $.28^{*}$ \\
Rule/Group Conformity & .07 & -.16 \\
\hline
\end{tabular}

Note. Significance at the $* p<.05$ level, 2-tailed.

\section{Discussion and Conclusions}

There is still much to learn in the study of teaching leadership to youth and how youth view leadership. This study not only aimed to identify the beliefs and attitudes toward leadership among participants in VGSA, but also examined how these beliefs and attitudes might relate to youth's problem-solving style. It was found that even though the VGSA program recruits gifted and talented students, the evidence indicates that these students did not have KAI scores outside the normal distribution associated with the general population (Kirton, 2015). 
There has been little published using the LABS-III, and more research is needed to identify how it relates to other key inventories used in the study of leadership. While there is no evidence of benchmark scores, there is evidence to support those proponents of Eco-Leadership suggest it is better to have higher levels of systemic thinking and lower levels of hierarchical thinking among those providing leadership to organizations in the modern, knowledge driven economy (Cletzer, 2016). Interestingly, mean scores reported from the VGSA students in this study are not all that different than the mean scores of college students reported by Fisher et al. (2015) in hierarchical thinking, but were slightly lower in systemic thinking. While some authors have found women to present lower levels of hierarchical thinking (Cletzer, 2016), this study could not support a relationship.

Findings in this study support the theoretical independence of problem-solving style, and one's attitudes and beliefs toward systemic thinking and hierarchical thinking. Said differently, one may be more adaptive or more innovative in their problem-solving style, while exhibiting high or low levels of hierarchical thinking and systemic thinking. It appears that the LABS-III is likely a measure of affect or preference of values towards leadership; meaning there is a valuation of preference that has no significant correlation with one's KAI score. It is interesting to note that the Efficiency sub-score had a small positive relationship with both hierarchical and systemic thinking, with the systemic thinking correlation being statistically significant. The small correlations indicate that the more adaptive one may be in style, the higher one may place value in systemic thinking. The Efficiency sub-score does have similarities with Weber's analysis of bureaucratic structure (as cited in Kirton, 2011), with more adaptive individuals having a preference for structure. However, the small correlation provides little evidence of a relationship and suggests the systemic scale of the LABS-III is not a pure measure of leadership attitudes and beliefs with respect to problem-solving styles.

Because VGSA students are a self-selecting group and have many things in common, the conclusions of this study are limited to the participants associated with the VGSA program. However, findings may apply to similar groups of youth who form together with the same purpose. Given this limitation there is still evidence to support the independence of problemsolving style as it relates to the LABS-III measure of attitudes and beliefs on leadership. It is pejorative to indicate that more adaptive or more innovative individuals are better leaders. Further, it is psychologically harmful to indicate to adolescents that they should be more adaptive or be more innovative; especially when they are the most vulnerable in forming their identity during this phase of their growth in becoming a leader (Hanks et al., 2015).

\section{Recommendations}

Empirical studies of ecological approaches to leadership are rare. When the fundamental unit of study changes from individuals, to discrete variables, to the complex adaptive system, studies become more difficult. It is likely due to this difficulty that "the vast majority of published work [on ecological views of leadership] relies on a conceptual approach rather than an empirical one" (San Martin Rodriguez, Beaulieu, D’Amour, \& Ferrada-Videla, 2005, p. 133). However, by studying leadership from an ecological perspective, we may expand our understanding of leadership from "the isolated, role-based actions of individuals to the innovative, contextual interactions that occur across an entire social system” (Lichtenstein et al., 
2006, p. 2). We also "increase the relevance and accuracy of leadership theory by exploring how leadership outcomes are based on complex interactions, rather than 'independent' variables" (Lichtenstein et al., 2006, p. 2). More research is warranted to gather more data with regard to the ecological approaches to youth, especially given the calls from the literature indicating EcoLeadership is the future perspective of leadership. There is no other age group of individuals more affected by this view.

This study found no relationship between total KAI scores of youth participating in the VGSA program and the LABS-III inventory indicating attitudes and beliefs towards leadership. More research is needed to confirm this theoretical relationship among other age groups and other populations. Attitudes and beliefs may change through one's lifespan of growing as a leader (Hanks et al., 2015), and, thus, the empirical examination of ecological views of leadership need to continue to be examined not only to determine if a relationship exists between problem-solving style and beliefs about leadership, but perhaps at what age a relationship may exist between these variables, if a relationship were to exist.

Even as proponents of the ecological perspective of leadership view high levels of systemic thinking and low levels of hierarchical thinking as more favorable, leadership educators who work with youth should not place favor on those who are more adaptive or who are more innovative. KAI scores are associated with one's personality, with evidence supporting problemsolving style is innate and stable (Kirton, 2011). Suggesting to youth that they should identify to be someone they are not, may cause psychological harm. Curricula should be developed to assist youth volunteer leaders to assist them in not making this mistake.

\section{References}

Allen, K. E., Stelzner, S. P., \& Wielkiewicz, R. M. (1999). The ecology of leadership: Adapting to the challenges of a changing world. Journal of Leadership \& Organizational Studies, 5(2), 62-82. doi:10.1177/107179199900500207

Andenoro, A. C., Allen, S. J., Haber-Curran, P., Jenkins, D. M., Sowcik, M., Dugan, J. P., Osteen, L. (2013). National leadership education research agenda. 2013-2018: Providing strategic direction for the field of leadership education. Retrieved from http://leadershipeducators.org/ResearchAgenda

Ary, D., Jacobs, L. C., Sorensen, C., \& Walker, D. (2013). Introduction to research in education ( $9^{\text {th }}$ ed.). Belmont, CA: Wadsworth Cengage Learning.

Avolio, B. J., Sivasubramaniam, N., Murry, W. D., Jung, D., \& Garger, J. W. (2003).Development and preliminary validation of a team multifactor leadership questionnaire. In C. L. Pearce, \& J. A. Conger (Eds.) Shared leadership: Reframing the hows and whys of leadership (pp.143-172). Thousand Oaks, CA: Sage Publications, Inc.

Capra, F. (1996). The web of life. New York, NY: Doubleday. 
Cohen, J. (1998). Statistical power analysis for the behavioral sciences $\left(2^{\text {nd }}\right.$ ed.). Hillsdale, NJ: Lawrence Erlbaum Associates.

Cletzer, D. A. (2016). Eco-leadership in practice: A mixed methods study of county 4-H programs (Doctoral dissertation). Retrieved from https://vtechworks.lib.vt.edu/bitstream/handle/10919/73652/Cletzer_DA_D_2016.pdf?s quence $=2$

Colarelli, S. M., (1998). Psychological interventions in organizations: An evolutionary perspective. American Psychologist, 53(9), 1044-1056. doi:10.1037/0003066X.53.9.1044

Friedel, C. (2014). The value of adaption and innovation as a function of diversity. In N. Erbe (Ed.) Approaches to managing organizational diversity and innovation (pp. 63-81). Hershey, PA: IGI Global. Retrieved from http://www.igi-global.com/chapter/the-valueof-adaption-and-innovation-as-a-function-of-diversity/108471

Fischer, D., Wielkiewicz, R. M., Stelzner, S. P., Overland, \& Meuwissen, A. S. (2015). Changes in leadership attitudes and beliefs associated with the college experience: A longitudinal study. Journal of Leadership Education, 14(1), 14-32. doi:1012806/V14/I1/R2 Hanks, S. K., Kaufman, E. K., Friedel, C. R., Clegorne, N. A., Seibel, M. M., Brunton, K. C., \& Burbaugh, B. J. (2015). A model of leader development across the life span. Virginia Cooperative Extension, 104P, 1-7.

Hanna, M.T. \& Freeman, J. (1984). Structural inertial and organizational change. American Sociological Review, 49(April), 149-164.

Katz, D., \& Kahn, R. S., (1978). The social psychology of organizations (2 ${ }^{\text {nd }}$ ed.). New York: Wiley.

Kelly, J. G., Ryan, A. M., Altman, B. E., \& Stelzner, S. P. (2000). Understanding and changing social systems: An ecological view. In J. Rappaport, \& E. Seidman (Eds.), Handbook of Community Psychology (pp. 133-159). New York, NY: Plentum.

Kirton, M. J. (2011). Adaption-innovation: In the context of diversity and change. New York, NY: Routledge.

Kirton, M. J. (2015). Kirton adaption-innovation inventory manual ( $3^{\text {rd }}$ ed.). Newmarket, Suffolk, U.K.: Occupational Research Centre.

Kirton, M. J. (2009). KAI certification course workbook. KAI Distribution Center Ltd.

Kirton, M. J. (2013). KAI theory workbook. KAI Distribution Center Ltd.

Lichtenstein, B. B., Uhl-Bien, M., Marion, R., Seers, A., Orton, J. D., \& Schreiber, C. (2006). Complexity leadership theory: An interactive perspective on leading in complex adaptive systems. Emergence: Complexity and Organization, 8(4), 2-12. 
Lowhorn, G. L. (2011). A confirmatory factor analysis of the leadership attitudes and beliefs scale-III. International Journal of Arts and Sciences, 4(6), 284-296.

National Research Council. (2009). Transforming agricultural education for a changing world. National Academies Press.

Northouse, P. G. (2013). Leadership theory and practice (6th ed.). Thousand Oaks, CA: Sage.

Posner, B. Z. (2004). A leadership development instrument for students: Updated. Journal of College Student Development,45(4). 443-456.

Rost, J. C. (1997). Moving from individual to relationship: A postindustrial paradigm of leadership. Journal of Leadership \& Organizational Studies, 4(4), 3-16.

San Martín-Rodríguez, L., Beaulieu, M.-D., D'Amour, D., \& Ferrada-Videla, M. (2005). The determinants of successful collaboration: A review of theoretical and empirical studies. Journal of Interprofessional Care, 19(s1), 132-147. doi: 10.1080/13561820500082677

Selby, E. C., Treffinger, D. J., Isaksen, S. G., \& Powers, S. V. (1993). Use of the Kirton adaption-innovation inventory with middle school students. Journal of Creative Behavior, 27(4), 223-235.

Wielkiewicz, R. M. (2000). The leadership attitudes and beliefs scale: An instrument for evaluating college students' thinking about leadership and organizations. Journal of College Student Development, 41(3), 335-347.

Wielkiewicz, R. M. (2002). Validity of the leadership attitudes and beliefs scale: Relationships with personality, communal orientation, and social desirability. Journal of College Student Development, 43(1), 108-118.

Wielkiewicz, R. M., \& Stelzner, S. P. (2005). An ecological perspective on leadership theory, research, and practice. Review of General Psychology, 9(4), 326-341. doi: 10.1037/10892680.9.4.326 


\section{Author Biographies}

Curtis R. Friedel, Ph.D., is an Assistant Professor and Director of the Center for Cooperative Problem Solving in the Department of Agricultural, Leadership, and Community Education at Virginia Tech. His scholarship includes the study of problem-solving teams working together as leaders. Email: cfriedel@vt.edu.

D. Adam Cletzer is an Assistant Professor at the University of Missouri researching ecological approaches to leadership and leadership development, as well as teaching graduate and undergraduate leadership and communication courses. He received a doctorate from Virginia Tech in 2016. Email: cletzerd@ missouri.edu

Sarah A. Bush is a Ph.D. student in the Department of Agricultural, Leadership, and Community Education at Virginia Tech. Her scholarship focuses on youth and adult leadership program development and evaluation. Email: $\underline{\text { sabush17@ vt.edu }}$

J. Danielle Barber, is a Graduate Research Assistant and Ph.D. student in the Department of Agricultural, Leadership, and Community Education at Virginia Tech. Her research includes the study of Kirton's adaption-innovation theory and how it can be used for leadership development. Email: dbjeane@ vt.edu 